\title{
[ 440$]$
}

\section{VII.}

Einige mineralogifche Neuigkeiten,

aus einem Schreiben des Hrn. Gelheimen Finanzrath Gerhard.

Eerlin d. 15. Nor. 1913 .

- Unfer verdienftroller $\mathrm{Klaproth}$ hat den Weifsftein aus thren Landen unterluclut, und gefunden. dafs er weit mehr Kiefelerde als der Feldfpath enıbält. Er befteht nämlich in roo Theilen aus so Thln. Kiefelerde, 12 Thln. Thonerde, 1,5 Thln. Eifenoxyd, 5 Thln. Kali und o,5 Thln. Waffer *).

Der fogenannte dichte Feldfpath von Siebenlehn bei Freyberg betieht in soo Theilen aus $5 x$ Thln. Kiefelerde, 3o,5 Thln. Thonerde, 11,25 Thln. Kalk, i, 75 Thln. Eifenoxyd, 4 Thln. Natron und 1,25 Thln. Waffer; er ift allo auch kein Feldfpath ${ }^{\star \star}$ ).

*) Nach Vauquelin's Aualylo cnthält in roo Theilen, Feldipath wafterheller

GiKi.E., 20 Th. E., 2 Kalk, I 4 Kali -

grūner alls Sibirien

$\begin{array}{lllll}62,8 & 17,2 & 3 & 13 & 180 x ., 3 \text { Verlult }\end{array}$

blätriger (Petunze)

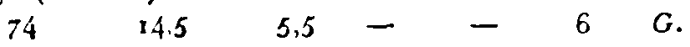

*) Nach Klaproth's Analylo enthält Saulfure's Jade, weicho Hr Hau y dem Feldfpatbe unter dem Namen Feldfpatk tenace beigefelt, in 100 Theilen $49 \mathrm{Ki}$. E., 2/ Th. E., xo $\frac{x}{2}$ Kalk, $3 s$ Magnefia, $5 \frac{1}{2}$ Natron und $6 \frac{x}{2}$ Eilenoxyd. welchem dip Mifchung des fogenannten dichten Fetdlipaths allo fehr nabe kö̈mmt.

G. 


\section{[ $44 \mathrm{I}]$}

Ich habe von Hrn. Kriegsrath Eversmann aus Hagen in Weftphalen, bei feiner Durchreife aus Rulsland, eine fchöne Sa:nunlung von Groflulur erhalien, und gefunden, dals der Groffular nicht blos in der Leucit-Kiyliallifition, fondern auch in dem gewöhnlichen Granat-Dodecaeder und in 3feitigen Pyramiden vorkonınt. In Feuer verbält er lich ganz wie Granat. Auch in feinen Beftandiheilen kommt er mit diefem überein. Er kann allo keine befondere Gattung ausmachen, fondern iit Granat. Manche Kryftalle haben inwendig einen Kern, welther entweder ein Weilsfte in ader ein vulkanifches Product ift. Er zerfallt zu einem weifsen Pulver, wie Leucit.

\section{VIII.}

Naturwiffenfchaftliche Preisaufgaben der Kön. Gejelljchafi fiir Norwegens Wohl.

Eine ftreng fyftematifche Darftellung der chemilchen Theorie der neueren $\mathrm{Na}$ turphilofophen, mit Anwendung fowohl auf die Operationen der Natur in ihren organifchen und unorganirchen Phinomenen, als auf die gewöhnlichen chemifchen Experimente.

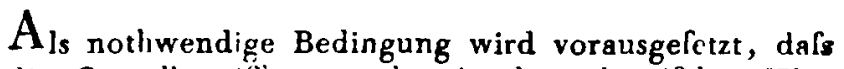
die Grundbegrifie von den in den chemifchen Wir. kungskreis eingreifenden Potenzen auf das genauefte und eine firengere Vernunft-Kritik zufriedenftellend befiimmt werclen, und dafs man niclut zu Ahnungen, dunkeln Gefühlen und poetifchen Fictionen feine Znfluchir nehme. In den Anmerkungen wünlcht man hingewielen zu werden, auf die neuere chemifche 